\title{
A case series of pneumothorax, pneumomediastinum and surgical emphysema in coronavirus disease 2019 (COVID-19)
}

\author{
Karl Jackson, Avinash Aujayeb^ \\ Respiratory Department, Northumbria Healthcare NHS Foundation Trust, Newcastle, UK \\ Contributions: (I) Conception and design: Both authors; (II) Administrative support: Both authors; (III) Provision of study materials or patients: \\ Both authors; (IV) Collection and assembly of data: Both authors; (V) Data analysis and interpretation: Both authors; (VI) Manuscript writing: Both \\ authors; (VII) Final approval of manuscript: Both authors. \\ Correspondence to: Dr. Avinash Aujayeb, MMBS, MRCP. Northumbria Healthcare NHS Foundation Trust, Care of Tracy Groom, Northumbria Way, \\ Cramlington, Northumberland, NE23 6NZ, UK. Email: avinash.aujayeb@nhct.nhs.uk.
}

\begin{abstract}
Background: The coronavirus disease 2019 (COVID-19) pandemic has been ongoing for nearly 18 months now and whilst randomized trials identify appropriate treatments, observational data increases knowledge around the real-life effects of COVID-19. Air leak in the context of acute lung injury is not a new phenomenon and usually associated with ventilation-induced lung injury. Air leaks (pneumothorax and pneumomediastinum) in the context of COVID-19 are being increasingly described. We sought to add to the literature by performing a local case review.

Methods: Northumbria Healthcare NHS Trust serves a population of approximately 600,000 in the North East of the United Kingdom. The records of all COVID-19 inpatients between March 2020 till January 2021 were analyzed. Local Caldicott approval was granted. Basic demographics and outcomes were collected. Descriptive statistical methodology was applied.

Results: Thirty-two air leaks were identified out of 2,827 inpatients, giving an incidence of $1.1 \%$. The patients were predominantly male, elderly and with a higher-than-normal body mass index (BMI). There was no relation to previous respiratory disease and ventilation. Air leaks occurred late, signifying progressive lung injury. Fifteen deaths occurred in this specific cohort.

Conclusions: Air leaks are rare but carry significant morbidity and mortality. Knowledge of this evidence can thus enable patient centered decisions about prognostication. Analysis of large data sets will shed further light on this association.
\end{abstract}

Keywords: Coronavirus disease 2019 (COVID-19); pneumothorax; pneumomediastinum; surgical emphysema

Received: 11 Apr 2021; Accepted: 30 June 2021; Published: 30 September 2021.

doi: 10.21037/asj-21-14

View this article at: https://dx.doi.org/10.21037/asj-21-14

\section{Introduction}

Coronavirus disease 2019 (COVID-19) is a multi-system disease caused by the severe acute respiratory syndrome coronavirus 2 (SARS-CoV-2). Since the World Health Organization declared a pandemic in early 2020, there have been cases nearly 126 million cases globally and 3 million deaths at the time of writing (1). Typical radiological findings include bilateral, multi-lobar, posterior, peripheral, and basal ground-glass opacity (GGO) with or without consolidation (2). Atypical features are often pleuro-parenchymal or mediastinal associated with air leaks (pneumothorax and/ or pneumomediastinum and/or surgical emphysema) (2). The largest case series by Martinelli et al. showed the development of pneumothorax in approximately $1 \%$ of

\footnotetext{
^ ORCID: 0000-0002-0859-5550.
} 
COVID-19 inpatients. Mechanical ventilation and previous lung disease were not risk factors and the authors cautioned against nihilism (3). Mortality is not seemingly ascribed to air leaks (3). Observational case series through rigorous searches of health data sets can capture the true incidence of, and inform local as well as global practice. We thus sought to add to the existing literature by performing a local case review. We present the following article in accordance with the STROBE reporting checklist (available at https://asj. amegroups.com/article/view/10.21037/asj-21-14/rc).

\section{Methods}

\section{Materials and methods}

All COVID-19 inpatients in Northumbria Healthcare NHS Foundation Trust in the North East of England from 1st March 2020 until 31st of January 2021 were identified. All chest X-rays (CXR) and chest computed tomography (CT) reports were searched for "surgical emphysema" and "pneumothorax" and "pneumomediastinum". Positive reports were identified and independently verified. Demographics and outcomes were collected. Informed consent was not required due to the nature of this anonymized retrospective analysis and nationwide provisions for the use of confidential patient information without consent for COVID-19 purposes. Caldicott approval was granted from Northumbria HealthCare NHS Foundation Trust (RPI-1279). The study was conducted in accordance with the Declaration of Helsinki (as revised in 2013).

\section{Statistical analysis}

Basic statistical methodology was applied. Continuous variables are presented as mean ( \pm range) and categorical variables as percentages where appropriate.

\section{Results}

During the defined period which spanned first and second waves, out of 2,827 inpatients with COVID-19, 32 (1.1\%) patients with air leaks were identified. Mean age was 63 years (range, 29-91 years); 27 (84\%) were male; all were white Caucasian except one (East Asian). Seventeen were ex-smokers, 12 never smokers and 2 were current smokers. There was no documented marijuana smoking. Comorbidities were treated chronic obstructive pulmonary disease (COPD) (4), asthma (5) and hypertension (5). Most patients did not have pre-existing documented lung disease, although 13 (41\%) were smokers. None of those patients had enough accumulated pack years to develop COPD. One patient had a previous pneumothorax. Median clinical frailty score (CFS) was 2 (range, 1-6), mean body mass index (BMI) was $27.6 \mathrm{~kg} / \mathrm{m}^{2}$ (range, $18.5-46.7 \mathrm{~kg} / \mathrm{m}^{2}$ ), mean height $1.7 \mathrm{~m}$ (range, $1.55-1.9 \mathrm{~m}$ ). Mean number of days to development of air leak was 13 (range, 1-120). Fifteen patients have died. The inspired fraction of oxygen $\left(\mathrm{FiO}_{2}\right)$ at the time of air leak development was 0.21 (air) in 7 patients, 0.24 in $1,0.35$ in 2, 0.4 in 1 and 0.9 (15 liters via non-rebreathe bag) in 3 . Seventeen (53\%) patients were on continuous positive airways pressure (CPAP) or mechanical ventilation. Ten patients were on CPAP with positive end expiratory pressures (PEEP) between 10 and 12 centimeters $(\mathrm{cm})$ of water. Seven patients were on mechanical ventilation (one via a tracheostomy) on PEEPs between 12 and $16 \mathrm{~cm}$ and $\mathrm{FiO}_{2}$ ranging from 0.75 to 1 . The annexed supplementary material summarizes the air leaks and respective outcomes (Table S1). Table 1 below summarizes the outcomes according to the type of air leaks

Two deaths were directly attributable to a pneumothorax. This is explained in greater detail below. All the pneumothoraces that were large $(n=3)$, according to British Thoracic Society criteria (4), had intercostal drainage. All other pneumothoraces were small.

\section{Discussion}

COVID-19 causes diffuse alveolar damage (6). Rupture of any alveolar sacs combined with pleural porosity will lead to pneumothorax. Subsequent air leaks can penetrate into the mediastinum and skin via the Macklin effect, causing pneumomediastinum and surgical emphysema. The Macklin effect, described in 1939, is the movement of air along the sheaths of the pulmonary vasculature from the alveoli into the mediastinum (7). "Lung frailty" and "architectural disruption" seems to be the etiological factor rather than ventilation associated lung injury $(5,6,8)$. The majority of patients were male, had a higher-than-normal BMI and were White Caucasian, reflecting local demographics in the North East of England.

Two deaths were directly attributable to a pneumothorax. One patient was elderly, frail with a CFS of 6, early dementia, an acute cerebrovascular incident. He acquired COVID-19 as an inpatient and developed subsequent respiratory failure. He then developed a large pneumothorax 
Table 1 Summary of patient outcomes according to type of air leak

\begin{tabular}{|c|c|c|c|c|c|c|}
\hline Variables & $\begin{array}{c}\text { Isolated } \\
\text { pneumothorax }\end{array}$ & $\begin{array}{c}\text { Isolated } \\
\text { pneumomediastinum }\end{array}$ & $\begin{array}{l}\text { Pneumomediastinum } \\
\text { and surgical } \\
\text { emphysema }\end{array}$ & $\begin{array}{l}\text { Pneumomediastinum } \\
\text { and surgical } \\
\text { emphysema and } \\
\text { pneumothorax }\end{array}$ & $\begin{array}{l}\text { Pneumothorax } \\
\text { and surgical } \\
\text { emphysema }\end{array}$ & $\begin{array}{l}\text { Pneumothorax and } \\
\text { pneumomediastinum }\end{array}$ \\
\hline Total number & 11 & 7 & 5 & 6 & 1 & 2 \\
\hline Deaths & 3 & 0 & 5 & 5 & 1 & 1 \\
\hline $\begin{array}{l}\text { Total number } \\
\text { on mechanical } \\
\text { ventilation at } \\
\text { the time of } \\
\text { leak }\end{array}$ & 0 & 0 & 2 & 2 & 1 & 1 \\
\hline
\end{tabular}

CPAP, continuous positive airways pressure.

with significant distress and agitation and was thus palliated. Another patient had a CFS of 6 and end-stage COPD who presented with COVID-19 and a small pneumothorax. He was in significant respiratory failure and was palliated appropriately. Another patient developed a pneumothorax whilst receiving CPAP (ceiling of treatment established on admission) and was successfully treated with a small-bore chest drain, but developed progressive respiratory failure and was palliated. Martinelli et al. caution against nihilism in the treatment of pneumothorax (3), and our findings would replicate that. A timely, holistic and overall assessment of the patient is advised.

All patients who developed an isolated pneumomediastinum $(n=7)$ were managed conservatively and are still alive. All were discovered as an incidental finding on CT scans or CXRs. As such, it seems that an isolated pneumomediastinum is not an adverse prognostic development.

Of the 6 patients who developed a combination of pneumomediastinum, surgical emphysema and pneumothorax (unilateral or bilateral), only 1 survived. All had a number of small (12 Fg) and large bore (24 Fg) drains placed either intrapleurally or subcutaneously, and 3 patients with massive surgical emphysema also had subcutaneous incisions made and vacuum dressings placed over. The surviving patient was a 46-year-old who presented with bilateral pneumothorax, surgical emphysema and pneumomediastinum. He was maintained on $\mathrm{FiO}_{2}$ of 0.4 until acute worsening prompted mechanical ventilation. A 24-Fg drain was inserted which improved the surgical emphysema but respiratory failure worsened significantly in the next 24 hours. He was referred and accepted for extracorporeal membrane oxygenation (ECMO) at a national tertiary center, and survived to discharge after a prolonged inpatient stay. The foregoing perhaps signals that the development of pneumothorax, surgical emphysema and pneumomediastinum is an adverse prognostic sign, unless "lung rest" via ECMO is possible. It should be noted that all other patients were referred for ECMO, but declined.

The only survivor out of the two patients who developed pneumothorax and pneumomediastinum was a 79-yearold patient whose PCR test was positive was 21 days prior to an acute presentation with chest pain. A CT thorax showed a pulmonary embolus, a small pneumothorax and pneumomediastinum. He was anticoagulated and oxygen saturations remained above $94 \%$ on air. He was discharged with no intervention required for his air leak. The other patient who died was on mechanical ventilation.

This is a single centre retrospective study with no control 
group, and thus significant limitations exist. For example, 4 patients with COPD, 7 with asthma and 17 ex-smokers having air leaks might sound significant in a cohort of 32, but we cannot infer substantial associations from this.

\section{Conclusions}

Air leaks in the context of COVID-19 are rare. Isolated pneumothorax and pneumomediastinum are not adverse prognostic signs, but the development of pneumothorax, surgical emphysema and pneumomediastinum on mechanical or non-invasive ventilation might be. Large data sets must be analyzed to confirm these findings.

\section{Acknowledgments}

Funding: None.

\section{Footnote}

Reporting Checklist: The authors have completed the STROBE reporting checklist. Available at https://asj. amegroups.com/article/view/10.21037/asj-21-14/rc

Data Sharing Statement: Available at https://asj.amegroups. com/article/view/10.21037/asj-21-14/dss

Conflicts of Interest: Both authors have completed the ICMJE uniform disclosure form (available at https://asj.amegroups. com/article/view/10.21037/asj-21-14/coif). The authors have no conflicts of interest to declare.

Ethical Statement: The authors are accountable for all aspects of the work in ensuring that questions related to the accuracy or integrity of any part of the work are appropriately investigated and resolved. The study was conducted in accordance with the Declaration of Helsinki (as revised in 2013). Informed consent was not required due to the nature of this retrospective analysis and nationwide provisions for the use of confidential patient information without consent for COVID-19 purposes. Caldicott approval was granted from Northumbria HealthCare NHS Foundation Tru (RPI-1279).

Open Access Statement: This is an Open Access article distributed in accordance with the Creative Commons
Attribution-NonCommercial-NoDerivs 4.0 International License (CC BY-NC-ND 4.0), which permits the noncommercial replication and distribution of the article with the strict proviso that no changes or edits are made and the original work is properly cited (including links to both the formal publication through the relevant DOI and the license). See: https://creativecommons.org/licenses/by-nc-nd/4.0/.

\section{References}

1. COVID-19 Dashboard by the Center for Systems Science and Engineering (CSSE) at Johns Hopkins University (JHU) [cited 2021 Mar 25]. Available online: https:// coronavirus.jhu.edu/map.html

2. Caruso D, Polidori T, Guido G, et al. Typical and atypical COVID-19 computed tomography findings. World J Clin Cases 2020;8:3177-87.

3. Martinelli AW, Ingle T, Newman J, et al. COVID-19 and pneumothorax: a multicentre retrospective case series. Eur Respir J 2020;56:2002697.

4. MacDuff A, Arnold A, Harvey J, et al. Management of spontaneous pneumothorax: British Thoracic Society Pleural Disease Guideline 2010. Thorax 2010;65 Suppl 2:ii18-31.

5. Cut TG, Tudoran C, Lazureanu VE, et al. Spontaneous Pneumomediastinum, Pneumothorax, Pneumopericardium and Subcutaneous Emphysema-Not So Uncommon Complications in Patients with COVID-19 Pulmonary Infection-A Series of Cases. J Clin Med 2021;10:1346.

6. Konopka KE, Nguyen T, Jentzen JM, et al. Diffuse alveolar damage (DAD) resulting from coronavirus disease 2019 Infection is Morphologically Indistinguishable from Other Causes of DAD. Histopathology 2020;77:570-8.

7. Macklin CC. Transport of air along sheaths of pulmonic blood vessels from alveoli to mediastinum: clinical implications. Arch Intern Med (Chic) 1939;64:913-26.

8. Lemmers DHL, Abu Hilal M, Bnà $\mathrm{C}$, et al. Pneumomediastinum and subcutaneous emphysema in COVID-19: barotrauma or lung frailty? ERJ Open Res 2020;6:00385-2020.

doi: 10.21037/asj-21-14

Cite this article as: Jackson K, Aujayeb A. A case series of pneumothorax, pneumomediastinum and surgical emphysema in coronavirus disease 2019 (COVID-19). AME Surg J 2021;1:13. 
Tables S1 Full data table of all patients with air leaks, describing demographics, presentation and outcomes

\begin{tabular}{|c|c|c|c|c|c|c|c|c|c|c|c|c|c|c|c|}
\hline Age, years & Sex & Ethnicity & Smoking & Co-morbid & CFS & BMI & $\mathrm{Ht}$ & Ptx/PMN & Symptoms & Ward/ICU & $\begin{array}{l}\text { Oxygenation }\left(\mathrm{FiO}_{2}\right) \text { at } \\
\text { the time of } \mathrm{Ptx}\end{array}$ & Treatment & Outcome & $\begin{array}{l}\text { Days from admission } \\
\text { to } \mathrm{Ptx}, \mathrm{pnm}\end{array}$ & Mode of diagnosis \\
\hline 91 & M & White & Ex & Stroke, IHD & 6 & 25.7 & 1.61 & Right Ptx & $\begin{array}{l}\text { Cough, fevers, } \\
\text { dyspnoea }\end{array}$ & Ward & 0.9 & Con & Death & 12 & Change in condition \\
\hline 75 & M & White & Ex & AAA repair & 1 & 25 & 1.55 & Left Ptx & Cough fever & Ward & 0.24 & Con & Alive & 12 & Incidental \\
\hline 65 & M & White & Ex & COPD, CCF & 2 & 29.8 & 1.72 & Right Ptx & $\begin{array}{l}\text { Lethargy, loss of } \\
\text { appetite }\end{array}$ & Ward & CPAP, 0.6 & $12 \mathrm{Fr}$ & Alive & 13 & Change in conditior \\
\hline 85 & M & White & Ex & COPD, AF, BP & 4 & 18.5 & 1.8 & Left Ptx & Cough, fever & Ward & 0.9 & Con & Death & 22 & Change in condition \\
\hline 67 & M & White & Current & $\begin{array}{c}\text { Previous stroke, type } 2 \\
\text { DM, emphysema and } \\
\text { combined pulmonary } \\
\text { fibrosis, previous ptx } \\
\text { and pleurodesis }\end{array}$ & 6 & 23 & 1.65 & Right Ptx & Dyspnoea & Ward & 0.28 & Con & Alive & 1 & $\begin{array}{c}\text { Seen on admission } \\
\text { X-ray }\end{array}$ \\
\hline 85 & M & White & Never & IHD & 4 & 23.2 & 1.74 & Left Ptx & Dyspnoea, pain & Ward & 0.21 & Con & Alive & 1 & Admission CTPA \\
\hline 54 & M & White & Ex & - & 2 & - & - & Right Ptx & $\begin{array}{l}\text { Cough, pain, } \\
\text { haemoptysis }\end{array}$ & Ward & 0.21 & Con & Alive & 1 & Admission CTPA \\
\hline 56 & M & White & Never & - & 2 & 22.5 & 1.82 & Left Ptx & Cough & Ward & 0.35 & $12,20,24 \mathrm{Fr}$ & Alive & 29 & Change in conditior \\
\hline 54 & M & White & Never & - & 0 & - & - & Right Ptx & Chest pain, cough & Ward & 0.21 & Con & Alive & 120 & X-ray \\
\hline 82 & M & White & Never & Asthma, hypertension & 1 & 24.3 & 1.75 & Right Ptx & $\begin{array}{l}\text { Cough, fever, confusion, } \\
\text { SOB }\end{array}$ & Ward & CPAP, 0.6 & $12 \mathrm{Fr}$ & Dead & 12 & Change in condition \\
\hline 32 & M & White & Never & - & 1 & - & - & Right Ptx & Cough, fever & $A$ and $E$ & 0.21 & Con & Alive & 1 & Admission Cxr \\
\hline 50 & M & White & Never & Asthma & 1 & 24.4 & 1.9 & PMN & Dyspnoea & $A$ and $E$ & 0.21 & con & Alive & 1 & Found on CTPA \\
\hline 57 & $\mathrm{~F}$ & White & Never & Asthma & 1 & 23.2 & 1.7 & PMN & Dyspnoea & Ward & 0.28 & con & Alive & 5 & Found on CTPA \\
\hline 61 & $\mathrm{~F}$ & White & Ex & - & 1 & 32.7 & 1.67 & PMN & Dyspnoea, fever & $\mathrm{ICU}$ & CPAP, 0.65 & con & Alive & 10 & Found on CTPA \\
\hline 49 & M & White & Ex & ALD, asthma & 2 & & & PMN & Dyspnoea, fever & $\mathrm{ICU}$ & CPAP, 0.5 & con & - & 5 & Incidental on cxr \\
\hline 63 & M & White & Ex & COPD, asthma & 1 & 27 & 1.84 & PMN & $\begin{array}{l}\text { Cough, fevers, } \\
\text { dyspnoea }\end{array}$ & $\mathrm{ICU}$ & CPAP, 0.3 & Con & Alive & 29 & Incidental \\
\hline 50 & M & White & Never & Asthma & 1 & 26.3 & 1.9 & PMN & Dyspnoea & Ward & 0.4 & con & Alive & 5 & Clinical change \\
\hline 76 & M & White & Ex & $\begin{array}{l}\text { CKD, RA, T2DM, liver } \\
\text { fibrosis, UC }\end{array}$ & 2 & 25.6 & 1.78 & PMN & Fever, dry cough & Ward & 0.9 & Con & Alive & 16 & $\begin{array}{l}\text { Inpatient CTPA- } \\
\text { incidental }\end{array}$ \\
\hline 61 & M & White & Never & - & 1 & 34.1 & 1.72 & PMN and SE & Cough, dyspnoea & Ward & CPAP, 0.9 & con & Dead & 10 & Clinical change \\
\hline 76 & $\mathrm{~F}$ & White & Never & Asthma, CKD, BP, OSA & 4 & 36.2 & 1.62 & PMN and SE & Dyspnoea, cough & Ward & CPAP, 1 & con & Dead & 4 & - \\
\hline 49 & M & White & Never & $\mathrm{IHD}$, type $2 \mathrm{DM}$ & 2 & 34.5 & 1.7 & PMN and SE & $\begin{array}{l}\text { Chest pain and } \\
\text { dyspnoea }\end{array}$ & $\mathrm{ICU}$ & $\mathrm{MV}$ & con & Dead & 12 & Clinical change \\
\hline 74 & M & White & Never & $\mathrm{BP}$, diabetes & 2 & 33 & 1.8 & PMN and SE & Dyspnoea, dry cough & $\mathrm{ICU}$ & MV & Con & Dead & 10 & Change in condition \\
\hline 80 & M & White & Never & Type 2 DM, CKD & 2 & 26.1 & 1.59 & PMN and SE & Fell down stairs, fever & Ward & CPAP, 0.55 & Con & Dead & 13 & Change in condition \\
\hline 68 & M & White & Never & - & 2 & 22.8 & 1.82 & Left Ptx and PMN & Dry cough & $\mathrm{ICU}$ & MV & $12 \mathrm{Fr}$ & Dead & 5 & Change in condition \\
\hline 79 & M & White & Current & - & 2 & 20.9 & 1.7 & Left Ptx and PMN & Pain & Ward & 0.21 & Con & Alive & 21 & Found on CTPA \\
\hline 63 & M & White & Ex & Type 2 DM & 1 & 31.1 & 1.7 & Right Ptx and SE & Dyspnoea & $\mathrm{ICU}$ & MV & Con & Dead & 8 & $\begin{array}{l}\text { Found when } \\
\text { intubated }\end{array}$ \\
\hline 57 & M & White & - & - & 1 & & & $\begin{array}{l}\text { Left Ptx, PMN and } \\
\text { SE }\end{array}$ & Cough & Ward & CPAP, 0.75 & $24 \mathrm{Fr}, \mathrm{SC}$ and $12 \mathrm{~F}$ & Dead & 6 & Clinical change \\
\hline 76 & M & White & Ex & Lung cancer & 2 & 24.8 & 1.58 & $\begin{array}{l}\text { Right Ptx, PMN and } \\
\text { SE }\end{array}$ & Facial swelling & Ward & 0.21 & Con & Dead & 1 & $\begin{array}{c}\text { Seen on admission } \\
\text { X-ray }\end{array}$ \\
\hline 51 & M & White & Ex & Aortic stenosis, BP & 1 & - & - & $\begin{array}{l}\text { PMN, SE and } \\
\text { bilateral Ptx }\end{array}$ & Dyspnoea, fever & Ward & Cpap, 0.5 & $2 \mathrm{SC}$ drains & Dead & 5 & Clinical change \\
\hline 29 & $\mathrm{~F}$ & White & - & Obesity, pregnant & 1 & 46.7 & 1.72 & $\begin{array}{l}\text { PMN, SE and } \\
\text { bilateral Ptx }\end{array}$ & Fever, dyspnoea & $\mathrm{ICU}$ & MV & $224 \mathrm{Fr}, 2 \mathrm{SC}$ & Dead & 3 & $\begin{array}{l}\text { Cxr on icu post } \\
\text { intubation }\end{array}$ \\
\hline 57 & $\mathrm{~F}$ & White & - & - & 2 & 34.2 & 1.64 & $\begin{array}{l}\text { PMN, SE and } \\
\text { bilateral Ptx }\end{array}$ & Cough, chest pain & ICU & MV & $\begin{array}{l}12 \mathrm{~F} \text { tried, } 24 \mathrm{~F} \text {, then } \\
\qquad 2 \mathrm{~F}\end{array}$ & Dead & 24 & Clinical change \\
\hline 46 & M & Asian & Ex & Previous pleural TB & 1 & 23.3 & 1.66 & $\begin{array}{l}\text { PMN, SE and } \\
\text { bilateral Ptx }\end{array}$ & Cough & $\begin{array}{l}\text { Ward then ICU- } \\
\text { required ECMO }\end{array}$ & 0.35 & $24 \mathrm{Fr}$, sub cut & Alive & 1 & $\begin{array}{c}\text { Seen on admission } \\
\text { X-ray }\end{array}$ \\
\hline
\end{tabular}

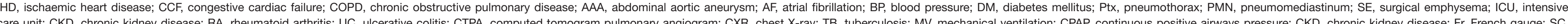
care unit; CKD, chronic kidney disease; RA, rheumatoid arthritis;
subcutaneous; ECMO extra-corporal membranous oxygenation 